\title{
Litigation benefits state-delivered medicine - but for how long?
}

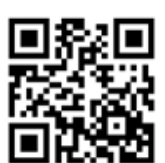

The soaring costs of private medical indemnity insurance for specialists in the higher-risk disciplines are preventing these thinly spread state-employed doctors from seeking extra income in the private sector - benefit-

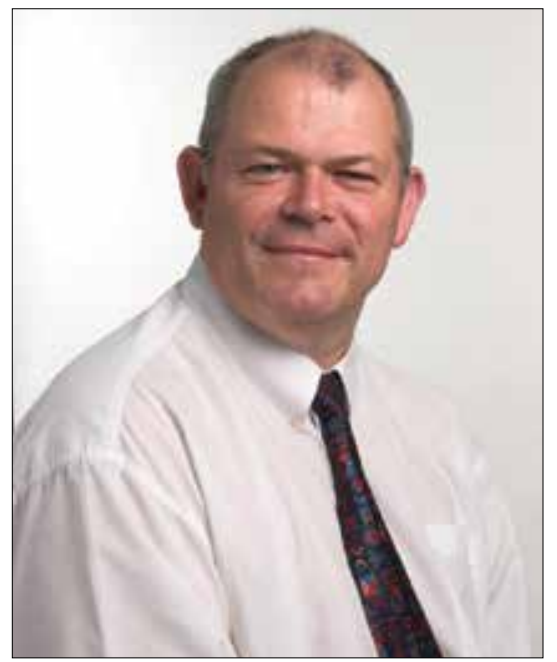

Dr Graham Howarth, Head of MPS Medical Services for Africa. ing state patients and improving professional supervision of junior colleagues.

This enigma came to the fore recently when a Cape Town obstetrician, who prefers to remain anonymous, responded to a series of articles in the $S A M J$ exposing the much-abused and controversial Remuneration for Work Outside the Public Service (RWOPS) practice. RWOPS was originally designed by the national health department as a retention tool and to enhance clinical skills not usually available in the public sector. However, top-end state medical salaries have since been hiked closer to what private consultants earn, lending weight to accusations of financial greed and state patient neglect against a significant minority of specialists. The controversy included disgruntled public sector junior consultants and medical officers complaining of a lack of teaching and availability of their senior colleagues, while several provincial health administrations launched investigations using medical aid claims records. More recently, national health minister Dr Aaron Motsaoledi, speaking at a South African Medical Association conference in Durban, blamed RWOPS abuse for junior doctors' deteriorating ability to conduct caesarean sections - with backing from his chief advisor on maternal and infant mortality surveillance, Prof. Jack Moodley. Motsoaledi has since imposed a silent moratorium on provinces cracking down on 'errant' specialists - until he has received a long-outstanding report with pragmatic recommendations on RWOPS from the Committee of Medical Deans.

\section{Although the dominant private} insurer, the London-based Medical Protection Society (MPS), offers reduced rates for limited private

practice, it imposes an annual gross RWOPS income ceiling of $R 240000$ per annum - a source of considerable dissatisfaction among higher-risk consultants.

\section{MPS RWOPS income ceiling on super-high risk rates}

Doctors in the public sector are fully covered by the state against 'adverse patient events', but those who also do RWOPS are forced to take out insurance just like their private counterparts. 
Herein lies the rub. Although the dominant private insurer, the London-based Medical Protection Society (MPS), the world's leading protection organisation for doctors, dentists and other healthcare professionals, offers reduced rates for limited private practice, it imposes an annual gross RWOPS income ceiling of R240 000 per annum - a source of considerable dissatisfaction among higherrisk consultants. A combination of patientclaims litigators becoming smarter, fast evolving (and expensive) medical technology and growing patient awareness have sent the overall cost of clinical negligence soaring beyond $150 \%$ in South Africa (SA) in recent years. SA is the only country to have incurred a mid-year MPS subscription hike for the highest-risk discipline, obstetrics, from R156 515 per annum to R187 830 in 2011. However, the most dramatic hike in obstetric MPS subscriptions is yet to come: they will leap from R330 000 per annum currently to R450 000 next year. Any extrapolation of these figures over the next 5 - 10 years (before even taking specialist overheads into account) seriously begs the question of who will be left in the private sector to deliver babies.

Co-authoring an article in the November SAMJ, Dr Graham Howarth, Head of MPS Medical Services for Africa, predicts that if SA obstetricians are unwilling to deliver in the private sector, the 170000 -plus annual national deliveries will move to the State sector, putting unprecedented pressure on already overburdened facilities and shifting liability to the State. He predicts fewer consultants in high-risk specialties, with those remaining practising defensive medicine, an absence or severe curtailing of private specialist obstetric care with paediatricians and opthalmologists reluctant to manage newborn children, fewer neurosurgeons in private practice, and fewer still with a primary interest in anything other than spinal surgery - and all restricted to larger urban areas. ${ }^{[1]}$ The second highest risk discipline is neurosurgery, with the subscriptions of those doing spinal work rising from R318 190 to R338 520 next year (or on the month-anniversary of the relevant specialist first joining MPS). This is followed by a category covering all surgeons (plastic, bariatric, orthopaedic, non-spinal and fertility medicine), where subscriptions jump from R131 080 per annum to R140 860. 'Below' these disciplines the increases are described by the MPS as 'relatively stable'.
The scale of the problem is reflected in SA's highest-ever medical damages settlement of R25 million in June 2013, to a patient who had undergone neurosurgery. A recent probe into the impressions of defensive medical practice and medical litigation among SA neurosurgeons conducted by the Division of Neurosurgery in the Faculty of Health Sciences at the University of Cape Town proves revealing. Annual operative caseloads were reported as being between 200 and 300 by $30 \%$ of respondents, with over a quarter (26.6\%) reporting more than 10000 cases over their practice lifetime. Most respondents (72.7\%) were in private practice, with just under a quarter $(22.5 \%)$ in state service, of whom two-thirds did some form of limited private practice. $^{[2]}$

A 10 -year study of maternity litigation in the UK (obstetric claims), via the National Health Service Litigation Authority (part of the NHS), shows that obstetrics accounted for $49 \%$ of all payouts. The trend is believed to be very similar in SA.

\section{An MPS survey of 322 of their SA members last month reveals that $70 \%$ of doctors received a complaint about the care they provide, with $57 \%$ citing clinical issues and $39 \%$ saying communication/manner and attitude was the reason behind the complaint.}

\section{Direct threat to NHI delivery}

Howarth said of the threat by litigation to specialist healthcare delivery, 'I think it points to the kind of future we'd have if people are not very careful. Private patients and providers, public patients and providers, politicians and policy pundits all have a vested interest in solving the problem - there is not a medical answer - it has to enter public debate.' There's also a growing body of opinion (through no fault of the MPS) that the rising costs of indemnity cover will dissuade young medical graduates from specialising in the disciplines most affected, thus aggravating the chances of our vital consultant-led district health teams ever being able to impact in a way that advances the ambitious and hugely necessary National Health Insurance.
The MPS has 30000 SA members and nearly 300000 members worldwide. Operating as a mutual society (not an insurer), it has among the strongest financial reserves of any healthcare indemnifier globally, with assets available to meet claims and other costs standing at close to R20 billion. It currently has well over a billion rand in outstanding claims and a 'substantial amount for matters that have already occurred but are not yet claims', boasting that it has never once turned down a proven claim of negligence. Any healthcare professional who was an MPS member at the time of a 'patient incident' is covered 'beyond the grave'. However, in an attempt to mitigate the steeply rising obstetrics subscriptions, the MPS is now offering considerably cheaper 'to the grave' cover, provided the obstetrician was an MPS member at the time of an incident or when they were sued - or that they informed the MPS of the adverse event while still a member. This 'risk-sharing' arrangement will cost R186 160 per annum. There are no immediate MPS data on this new product.

Time will tell whether obstetricians will gamble on avoiding even one settlement involving lifelong payments towards the upkeep of an impaired newborn infant. In the meantime, it's to the unenviable 'shelter' of the state sector - or overseas that many will go. An MPS survey of 322 of their SA members last month reveals that $70 \%$ of doctors received a complaint about the care they provided, with 57\% citing clinical issues and 39\% saying that communication/manner and attitude was the reason behind the complaint. A full $84 \%$ of doctors believe they now experience more complaints, with $44 \%$ considering the main cause to be easier access to lawyers and $43 \%$ believing it is because patients 'expect more'.

\section{Chris Bateman \\ chrisb@hmpg.co.za}

S Afr Med J 2015;105(1):13-14.

DOI:10.7196/SAMJ.9168

1. Howarth GR, Goolab B, Dunn RN, Fieggen AG. Public somnambulism: A general lack of awareness of the consequences of increasing medical negligence litigation. S Afr Med J 2014;104(11):752-753. [http://dx.doi.org/10.7196/SAMJ.8568]

2. Roytowski D, Smith TR, Fieggen AG, Taylor A. Impressions of defensive medical practice and medical litigation among South African neurosurgeons. S Afr Med J 2014;104(11):736-738. [http://dx.doi.org/10.7196/SAM].8336] 